\title{
Ever decreasing circles: speech production in semantic dementia
}

Article

Accepted Version

Meteyard, L., Quain, E. and Patterson, K. (2014) Ever decreasing circles: speech production in semantic dementia. Cortex, 55. pp. 17-29. ISSN 0010-9452 doi: https://doi.org/10.1016/j.cortex.2013.02.013 Available at https://centaur.reading.ac.uk/31376/

It is advisable to refer to the publisher's version if you intend to cite from the work. See Guidance on citing.

To link to this article DOI: http://dx.doi.org/10.1016/j.cortex.2013.02.013

Publisher: Elsevier

All outputs in CentAUR are protected by Intellectual Property Rights law, including copyright law. Copyright and IPR is retained by the creators or other copyright holders. Terms and conditions for use of this material are defined in the End User Agreement.

\section{www.reading.ac.uk/centaur}

\section{CentAUR}

Central Archive at the University of Reading

Reading's research outputs online 
Accepted / in press in Cortex.

EVER DECREASING CIRCLES: SPEECH PRODUCTION IN SEMANTIC DEMENTIA

Lotte Meteyard $^{*}{ }^{1}$ Emma Quain ${ }^{1}$ and Karalyn Patterson ${ }^{2}$

*Corresponding Author:

${ }^{1}$ School of Psychology and Clinical Language Sciences

Psychology Building

Whiteknights Campus

University of Reading

Reading, UK.

RG6 6AL

Email: 1.meteyard@ reading.ac.uk

Tel: +44(0)118378 8142

Fax: +44 (0)118378 4693

${ }^{2}$ Department of Clinical Neurosciences,

University of Cambridge

Addenbrooke's Hospital,

Cambridge

CB2 0SZ

Running head: Speech production in Semantic Dementia 
Accepted / in press in Cortex.

\section{Abstract}

We explored the impact of a degraded semantic system on lexical, morphological and syntactic complexity in language production. We analysed transcripts from connected speech samples from eight patients with semantic dementia (SD) and eight age-matched healthy speakers. The frequency distributions of nouns and verbs were compared for hand-scored data and data extracted using text-analysis software. Lexical measures showed the predicted pattern for nouns and verbs in hand-scored data, and for nouns in software-extracted data, with fewer low frequency items in the speech of the patients relative to controls. The distribution of complex morpho-syntactic forms for the SD group showed a reduced range, with fewer constructions that required multiple auxiliaries and inflections. Finally, the distribution of syntactic constructions also differed between groups, with a pattern that reflects the patients' characteristic anomia and constraints on morpho-syntactic complexity. The data are in line with previous findings of an absence of gross syntactic errors or violations in SD speech. Alterations in the distributions of morphology and syntax, however, support constraint satisfaction models of speech production in which there is no hard boundary between lexical retrieval and grammatical encoding.

\section{$\underline{\text { Key words }}$}

Semantic dementia, speech production, syntax, morphology, frequency 
Accepted / in press in Cortex.

\section{Introduction}

The relationship between lexico-semantic and grammatical information, particularly during speech production, is an enduring topic of argument and research (Bock, 1987; Bock and Warren, 1985; Chang, Dell, \& Bock, 2006; Dell, Chang, \& Griffin, 1999; V. S. Ferreira and Dell, 2000; Garrett, 1980; Goldrick, 2006; Levelt, Roelofs, \& Meyer, 1999; Schiller and Costa, 2006; Schriefers, Jescheniak, \& Hantsch, 2005; Vigliocco and Hartsuiker, 2002). Grammatical encoding and lexical retrieval are intimately related: during the early stages of production, a pre-verbal message is translated into lexico-semantic representations (words) that are assigned to particular roles (syntactic structures) to express the message (who did what and to whom) (Bock, 1999; Bock and Levelt, 1994; Garrett, 1980). At the lexical level, some grammatical and semantic distinctions correlate highly: e.g. nouns and verbs largely correspond to objects and actions (Vigliocco et al., 2006); the meanings of verbs correlate closely with the argument structures in which they can appear (Levin, 1993) and nouns are held to carry or define the syntactic information that controls their determiners (Schiller and Caramazza, 2006; Schiller and Costa, 2006; Schriefers et al., 2005). Some theorists propose that syntactic features are linked to or part of lexico-semantic (lemma) representations (Levelt et al., 1999) and constraint satisfaction models of language also propose a multi-dimensional role for the lexicon (Seidenberg and MacDonald, 1999). These models are most developed for language comprehension, but the frameworks can be applied to production. The 'lexicon' includes information about semantic, phonological and morphological features of words, as well as the argument structure for verbs, and the relative frequency or probability of a given element of information (Seidenberg and MacDonald, 2001). The constraint satisfaction approach does not place a hard boundary between the 
Accepted / in press in Cortex.

lexicon (single word meaning and single word forms) and syntax. Syntactic and morphological structures are emergent properties rather than stable, rule based representations that can be stored and retrieved holistically. Constraint satisfaction fits well with incremental speech production models (Timmermans, Schriefers, Sprenger, \& Dijkstra, 2012). In both cases, multiple sources of linguistic and nonlinguistic information are integrated in real time during production. There is limited pre-planning of utterances and the availability of information plays an important role in determining the structure of output. For example, concepts that are more salient (e.g. because they are animate, more imageable or presented earlier) are assigned more prominent grammatical roles (e.g. sentence subject) (Bock and Warren, 1985; McDonald, Bock, \& Kelly, 1993; Timmermans et al., 2012). This means that lexical selection plays an important part in determining the final structure of a sentence as well as its component words. In sum, there is evidence for a close interplay between lexical, morphological and local syntactic information (Bock, 1987; Dell et al., 1999; V. S. Ferreira and Dell, 2000; Patterson, Lambon Ralph, Hodges, \& McClelland, 2001; Vigliocco and Hartsuiker, 2002).

Neuropsychological evidence from patients with impaired semantic representations, on the other hand, is frequently reported as demonstrating independent impairment of semantic and grammatical processes (Kave, Leonard, Cupit, \& Rochon, 2007), which in turn would suggest a separation between lexical retrieval and grammatical encoding. Semantic Dementia (SD) is a progressive neurological condition, associated with degeneration of the anterior temporal lobes bilaterally, and manifesting as a fairly selective deterioration of conceptual and semantic information across all modalities of input and output, both verbal and non-verbal (Bozeat, Lambon 
Accepted / in press in Cortex.

Ralph, Garrard, Patterson, \& Hodges, 2000; Hodges and Patterson, 2007). The deterioration can be characterised as a gradual reduction in aspects of knowledge specific to individual concepts, paring semantic memory back to its barest and most general bones (Patterson et al., 2006; Warrington, 1975).

Lexical deficits in speech production are well documented in SD (Hodges and Patterson, 2007; Hodges, Patterson, Oxbury, \& Funnell, 1992; Patterson and MacDonald, 2006). Normal language processing, both receptive and expressive, depends on conceptual information that supports the semantic content of lexical items, and anomia is typically the first noticeable symptom of SD (Hodges and Patterson, 2007; Nickels and Howard, 2000). The narrative speech of SD patients displays a reliable pattern of light or vague terms (e.g. 'thing' and 'place', 'do' and 'go') in lieu of specific open class words (Kave et al., 2007; Meteyard and Patterson, 2009) and other lexical items tend to be from high frequency, high familiarity bands (Ash et al., 2006; Bird, Lambon Ralph, Patterson, \& Hodges, 2000; Patterson and MacDonald, 2006). Apart from this characteristic anomia, free speech in SD is considered fluent and basically intact as regards phonology and grammar (Wilson et al., 2010). Patients with SD make scarcely if any more phonological errors than healthy speakers in spontaneous speech, where the patients are only using words whose meanings they still know (Meteyard and Patterson, 2009; Patterson, in press; Sajjadi, Patterson, Tomek, \& Nestor, 2012; Wilson et al., 2010) They do not produce gross syntactic errors or differ from controls on measures such as the number of embeddings, proportion of words in sentences or verbs with inflections (Meteyard and Patterson., 2009; Wilson et al., 2010). 
Accepted / in press in Cortex.

The evidence for preserved phonology in SD patients' spontaneous speech is fairly consistent (Meteyard \& Patterson, 2009) but evidence for preserved morphological and syntactic processing is mixed. Kave et al (2007) completed an analysis of the lexical, morphological and syntactic characteristics of a single SD patient, $\mathrm{AK}$, at three different time points across 3 years and compared against a small control group. For part of the analysis, the authors used a set of measures developed to quantify aphasic speech production: Quantitative Production Analysis (QPA) (Saffran, Berndt, \& Schwartz, 1989). The patient was asked retell the Cinderella fairy-tale and in the latter-two time points needed story-relevant pictures to produce sufficient speech for analysis. Therefore, the data were in fact obtained from both familiar narrative and picture description tasks. The authors reported no difference between $\mathrm{AK}$ and the control group for the number of well-formed sentences, noun and verb phrase elaboration (i.e. the number of words in a noun or verb phrase), the number of arguments used per verb or the complexity of verb inflections and auxiliaries used. These results were contrasted against conceptual and lexical measures which showed a clear deterioration in conceptual knowledge. Breedin \& Saffran (1999) analysed both the comprehension and production of SD patient DM, and also used the QPA to analyse speech production. His performance was within the normal range on all measures. Using a very different technique requiring production of specific structures, Benedet et al. (2006) reported that a Spanish SD patient ILJ had difficulty in producing complex morphological forms, both inflectional and derivational. Furthermore, although able to generate typical Subject-Verb-Object sentences on demand, ILJ had problems with less typical constructions, such as relatives and passives. When asked for passives, which are rare in everyday spoken Spanish 
Accepted / in press in Cortex.

(though normal speakers can and do produce them on demand), ILJ tended to omit or substitute the required auxiliary or just produce an active sentence.

There have been four case-series studies of English-speaking SD patients, one exploring verb morphology and three analysing sentence content and structure. With regard to morphology, $11 \mathrm{SD}$ patients were impaired in producing and recognising the correct past-tense forms of irregular verbs, especially less frequent ones; the degree of this deficit was significantly correlated with the patients' comprehension impairment on a verb synonym task (Patterson et al., 2001). Of the case-series studies of SD speech content/structure, two used narrative descriptions from the Cookie theft picture. Bird, Lambon Ralph, Patterson \& Hodges (2000) reported on the lexical cohorts in the narratives of three SD patients sampled at three successive time points (across 2.5 years for two patients, and 6 years for the third patient). Over time, these cohorts revealed steady increases in word frequency and decreases in imageability because these two variables are negatively correlated. The ratio of nouns to total words decreased as lower frequency words dropped out of the patients' productions, whereas the ratio of verbs to total words remained unchanged due to the availability of high frequency, light verbs. Thus, easy access to very high frequency content words, which are mostly verbs, can lead (or actually mislead) researchers to the conclusion of a greater deficit for nouns than verbs in SD.

Patterson and MacDonald (2006) used Cookie theft descriptions to explore the lexical and syntactic characteristics of SD speech. Relative to matched controls, patients used a similar number of function words but fewer content words. There were somewhat fewer embedded constructions (e.g. "The boy who is stealing cookies is going to fall") in the patient than control samples and also fewer noun phrases 
Accepted / in press in Cortex.

following verbs. Patients used the light verb 'get' (in place of 'steal') and phrasal verbs such as the water is 'coming out' or 'coming down' (in place of 'overflowing'). This is in line with recent findings that SD patients use more generic, high frequency verbs to describe videos of actions when compared against controls (Meligne et al., 2011). Meteyard \& Patterson (2009) analysed open ended responses to questions about autobiographical events for eight SD patients. There was a notable absence of gross syntactic errors such as violations of word order or omissions of obligatory function words/inflections, but the patients as a group made significantly more substitution errors than normal speakers on both free and bound morphological elements.

Speech production in patients with SD clearly reflects their deficits in lexical access/activation, with a consequent increase in the use of high frequency and generic words and pronouns, all linked to a central semantic deterioration. There is minor but suggestive evidence of problems with complex morphology and local syntactic structures (such as embedded clauses or the passive form). For SD patients, production of both nouns and verbs is constrained to higher frequency more generic terms, and closed class words start to predominate in speech. In constraint satisfaction and incremental approaches to speech production, the morphological and syntactic structures that are produced are determined in part by the availability of information at the level of the lexicon. According to these approaches, the syntactic constructions of SD patients should reflect this difference in lexical retrieval and therefore differ from controls. As SD patients are forced to rely on high frequency forms, we might expect to see a greater use of syntactic forms that include easily available closed-class elements, such as prepositional phrases or interrogative 
Accepted / in press in Cortex.

pronouns ('Wh' words). With respect to morphological complexity, SD patients tend to substitute an equally complex inflection for bound morphology and also make substitution errors for free-standing closed class items (Meteyard and Patterson, 2009). This indicates that the selection of these items is disrupted when there is degradation of the specific semantic information needed to distinguish between a set of closely related options. SD patients may therefore produce fewer forms that require multiple inflections as they require more input from the semantic system to define and select required items. With respect to syntactic complexity, structures that require additional semantic information (e.g. relative clauses that add detail to a subject or object) may be vulnerable as they require exactly the kind of additional specific information that may be lost in SD. In contrast to these predictions, theories that propose a clear separation between lexical retrieval and syntactic encoding may make one of two predictions. (1) There will be only lexical level differences between patients and controls, and no difference in morphological or syntactic constructions (Breedin and Saffran, 1999). (2) If syntactic constructions are retrieved and produced holistically (F. Ferreira and Swets, 2002; Garrett, 1980), the semantic system may play a more general role in supporting the production of less typical and less frequent syntactic forms, regardless of the closed class elements that are included or their semantic content. This may parallel how the semantic system interacts with phonology (Woollams, Lambon Ralph, Plaut, \& Patterson, 2007). Specifically, more semantic support is needed to encode constituents of forms that are not highlyfrequent and therefore not regularly produced. In this case, we may see that SD patients use more typical forms and fewer less typical forms. Defining syntactic typicality is tricky, so the exploratory approach we have taken here is to use an existing metric that grades syntactic forms according to developmental acquisition 
Accepted / in press in Cortex.

(Voss, 2005). We therefore make the assumption that more typical forms are acquired earlier.

We know from previous work that SD patients show differences in the distribution of the frequency of lexical items, e.g. using more high frequency and fewer low frequency nouns and verbs (Bird et al., 2000). It is possible that differences in morphological and syntactic processing are present, but undetected by measures that are designed to detect the sorts of gross syntactic errors, grammatical ill-formedness and morphological simplification found in agrammatic/non-fluent profiles of aphasia (Breedin and Saffran, 1999; Kave et al., 2007; Saffran et al., 1989; Wilson et al., 2010). Instead, we need to look at the distribution of forms used by the patients, and how this compares to healthy controls.

This kind of work is labour and time intensive, and there are now a number of automated procedures that can be used to complete such analyses. We therefore took this opportunity to compare hand-scored and automatically processed measures for both lexical and grammatical dependent variables. For automated data analysis we have used two freely available softwares, GATE (Cunningham, Maynard, Bontcheva, \& Tablan, 2002; Cunningham et al., 2011) and ShaC (Voss, 2005). Automated softwares may offer increased opportunities to analyse large data sets, where they can be tailored to fit the questions of interest. 
Accepted / in press in Cortex.

\section{Method}

\subsection{Participants}

Eight patients with a clinical diagnosis of semantic dementia (SD), identified through the Memory and Cognitive Disorders Clinic or the Early Dementia Clinic at Addenbrooke's Hospital, Cambridge, UK, provided the speech samples analysed in this paper. Their diagnoses were based on the cognitive and neuroradiological criteria outlined by (Hodges et al., 1992) and were supported by neuropsychological testing. Seven of these patients were originally recruited to take part in a study of autobiographical memory, and form a subset of a larger group of SD patients for whom autobiographical memory results are published in Irish et al. (2011). One other patient (DV), who was too impaired to participate in the autobiographical memory study, had his free speech recorded before routine neuropsychological testing. Their mean age (at the time of completing the majority of neuropsychological tests) was 64.9 years $($ s.d. $=6.4)$, and they had spent an average of 13.6 years in formal education (s.d. = 3.2). Eight control participants were randomly selected from a set of fifteen recruited for the same autobiographical memory study; their mean age was 60.4 years $($ s.d. $=4.9)(\mathrm{t}(14)=2.0$ and $\mathrm{p}=0.06)$ with an average of 15.6 years $($ s.d. $=$ 3.2) in formal education $\left(\mathrm{t}(14)=\_0.912\right.$ and $\left.\mathrm{p}>0.3\right)$. Control participants were recruited from the MRC Cognition and Brain Sciences Unit volunteer panel. Details of the patients' neuropsychological profile can be found in Meteyard \& Patterson (2009, Table 1). 
Accepted / in press in Cortex.

\subsection{Connected Speech / Interview elicitation}

Seven participants took part in a semi-structured interview (approximately 30 to 60 minutes long) using the Autobiographical Memory Interview (Kopelman, Wilson, \& Baddeley, 1990; McKinnon, Miller, Black, Moscovitch, \& Levine, 2006; Nestor, Graham, Bozeat, Simons, \& Hodges, 2002). Each person was asked to recall specific memorable events that had happened on one day, from four life periods: before 18 years old, between 18 and 30, between 30 and 50, and something that happened in the last year. Participants were encouraged to talk at length about a given event. Typical topics were schooling, weddings, births, birthdays, holidays and work related events (e.g. first job, redundancies or retirement). Patient DV's speech sample was gathered from a conversation about current and recent day-to-day activities, collected the start of some neuropsychological tests. It therefore also covered autobiographical topics.

\subsection{Transcription}

Each interview was orthographically transcribed from the original recording by the first author using Express Scribe (v 4.15, NCH Swift Sound, www.nch.com.au/scribe). A minimal transcription style was used. Any items that could not be confidently transcribed (e.g. inaudible items) were marked with square brackets e.g. [and] or as a question mark in square brackets e.g. [?]. Utterances with these ambiguous items were not included in the syntactic analysis, nor were phrases that appeared repetitively as idiosyncratic discourse markers or filler terms ('I mean', 'I dunno'), direct responses to questions (yes, no) or immediate repetitions of questions asked by the experimenter. 
Accepted / in press in Cortex.

To avoid any issues with normality, all statistical comparisons are non-parametric. For the hand-scored lexical and morphological analyses, the full transcripts were used. For the automated extraction of nouns and verbs using GATE (Cunningham et al., 2002) and the syntactic analysis using ShaC (Voss, 2005), a sub-sample of each participant's transcripts were used. For the syntactic analysis, it was important to control for the number of analysed utterances. For both automated analyses transcripts had to be formatted correctly for parsing by the software and separated into clausal utterances.

The length was determined by the shortest transcript available, for the SD patient DV ( 100 clauses / 750 words) once it had been prepared to include only complete, identifiable clauses or phrases (e.g. a stand-alone noun phrase such as "red lighting"). Fragments that did not constitute complete clauses or identifiable phrases were deleted. For the remainder of participants, the first $\sim 100$ clauses / 750 words were taken, with every partial / ambiguous clause that was deleted replaced with the next whole one from later in the transcript. For all participants, this meant that responses to the first autobiographical question were analysed.

The following conventions were adopted: utterances were broken into clauses with one whole independent clause forming one utterance. A clause was defined as a subject and a predicate, with dependent clauses left as part of the independent clause sentence unit. Clauses following non-subordinating conjunctions (e.g. and, but, so) were treated as separate independent clauses. GATE and ShaC are canonically used for written text samples, so the transcriptions had to be prepared accordingly. The following were expanded: contractions of words (e.g. "cos" to "because" and "pr'aps" 
Accepted / in press in Cortex.

to "perhaps") and clitics (e.g. "didn't" to "did not") because GATE marked them as nouns if they were not expanded. In the case of self-corrections or the reverse, we took whichever form was correct (e.g. "I have to keep drying dry my eyes... er... drying my eyes" becomes "I have to keep drying my eyes"). Morphological errors were left in as these did not affect the parsing of the sentence (e.g. "that has made me cried a lot").

\subsection{Analysis}

For the hand-scored analyses (lexical, morphological and syntactic) the basic transcripts were loaded into Excel and various dependent measures were extracted. Hand-scoring of noun and verb tokens was completed by the first author. Automated extraction of nouns and verbs was completed using the GATE software (Cunningham et al., 2002; Cunningham et al., 2011) by passing each transcript as a .txt file through the ANNIE processing pack plus VP and NP chunker in GATE, and extracting the items coded as nouns or verbs. Hand-scoring for morphological and syntactic measures was completed by the first and second authors. Automated extraction of syntactic structures was completed by passing each transcript as a txt file through the ShaC functions rank_sentence_file('input file','templates.txt','output file') and rank_from_templates_score_list(1,' input file','templates.txt',Score). This allowed us to extract the number of utterances that fell into each ShaC complexity score.

\subsubsection{Lexical measures: Word Counts and Word Ratios}

The transcripts were exhaustively coded so that the following could be extracted: open class items (nouns, verbs, adjectives, adverbs), closed class items (all other items), noun and verb tokens, light verbs (e.g. be, come, do, get, go, have, make and 
Accepted / in press in Cortex.

move), light nouns (thing, stuff, place, type and one), demonstrative pronouns (this, that, these, those), interrogative pronouns (which, who, what, where, when) and indeterminate locative terms (here, there). The pronoun types were compared as a proportion of total closed class items. The following word ratios were computed: Open:Closed class, Light nouns:All Nouns, Light Verbs:All Verbs.

\subsubsection{Lexical measures: Frequency of noun and verb tokens}

We compared a word-form frequency analysis for hand-scored data (the nouns and verbs extracted for the above word count/word ratio analysis) and for items marked as nouns and verbs by the automated parsing in GATE. No attempt was made to correct the GATE parsing, as this analysis was meant as a first pass to see if automated lexical tagging would be reliable when compared against hand-coding. Celex log spoken word form frequency per million words (Baayen, Piepenbrock \& Gulikers, 1995) was extracted for noun and verb tokens. Items were sorted into seven bins, spanning the log values 0.0 to 3.5 in equal steps of 0.5 .

\subsubsection{Frequency of complex verb morphology: the auxiliary score.}

This measure, taken from Saffran, Berndt \& Schwartz (1989), scores morphological constructions according to their deviation from the simplest possible realisation of a verb (an uninflected stem form). Additional points are awarded for the use of inflections, auxiliaries and inflections on the auxiliaries, therefore higher values indicate increased complexity. For detailed guidelines see Saffran, Berndt \& Schwartz, (1989) and Rochon, Saffran, Berndt \& Schwartz (2000). To check coding reliability, the same 40 utterances were scored independently by the first and second author, with $100 \%$ agreement. 
Accepted / in press in Cortex.

\subsubsection{Frequency of syntactic constructions}

For hand-scored analyses, we used the sub-categorisation frames identified in Roland, Dick and Elman (2007), in which they established the relative frequency of these constructions in different English corpora. We completed analyses on these original constructions, and also a Roland+ set to which we added the following specific constructions: stand-alone Noun Phrase (NP), copula, intransitive + prepositional phrase $(\mathrm{PP})$, intransitive + Wh Clause, relative clause, transitive $+\mathrm{PP}+\mathrm{Wh}$ Clause, and connected phrases (phrasal elements connected by 'and'). Examples of all constructions are provided in Table 1. This extended scheme was created so that we could code more of the constructions in the transcripts and include relative clauses. The Roland+ scheme was constructed during initial exploratory coding. To check coding reliability, two patient transcripts were first coded separately by the first and second author, with $72 \%$ and $82 \%$ agreement. The second author then coded the remaining transcripts, and these were checked by the first author. Overall agreement was high, with an average of $88 \%$ for patient transcripts and $84 \%$ for control transcripts. Disagreements were resolved through discussion and revisiting the coding scheme.

For automated analyses, we used the scores that the ShaC parser assigns to each analysed utterance. These are based on the age at which constructions are acquired, the higher the score, the later the construction is acquired and the more complex it is assumed to be. We used score bins ranging from 0 to $>5$. From this we computed the proportion of utterances that fell into each score bin and compared this across patients and controls; as only one control participant had any utterances that received a score of 2 we removed this level from the final analysis. 
Accepted / in press in Cortex.

Table 1: Examples of syntactic constructions*

\begin{tabular}{|c|c|}
\hline Syntactic construction $^{\dagger}$ & Example taken from data \\
\hline $\begin{array}{l}\text { Connected phrases } \\
\text { - two phrases connected by 'and' }\end{array}$ & all just [baking in the sun] and [standing out there] \\
\hline $\begin{array}{l}\text { Copula } \\
\text { - the verb 'to be' used to join subject to } \\
\text { a noun phrase or adjective phrase }\end{array}$ & [this is something] I will never ever forget \\
\hline $\begin{array}{l}\text { Ditransitive } \\
\text { - a verb with two direct objects }\end{array}$ & they [gave me filing] \\
\hline $\begin{array}{l}\text { Gerund (verbal) } \\
\text { - noun phrase derived from a verb }\end{array}$ & he started [eating his sandwiches] \\
\hline $\begin{array}{l}\text { Intransitive } \\
\text { - verb with no object }\end{array}$ & and he [stayed] \\
\hline Intransitive + Prepositional Phrase & we were all [dressed [in the same colours]] \\
\hline Intransitive + Wh clause & the memory always [comes back [when I see the Olympics]] \\
\hline Noun Phrase (NP) & [lovely house] \\
\hline $\begin{array}{l}\text { Passive } \\
\text { - patient appears in subject location }\end{array}$ & it was [sponsored by Cadbury] \\
\hline $\begin{array}{l}\text { Perception Complement } \\
\text { - complement describing a perceived } \\
\text { experience }\end{array}$ & and that [smelt musty] \\
\hline $\begin{array}{l}\text { Prepositional Phrase (PP) } \\
\text { - phrase beginning with a preposition }\end{array}$ & [down the West valley] \\
\hline PP + to Infinitive Verb Phrase (VP) & waited [for the judge] [to say what he thought] \\
\hline $\begin{array}{l}\text { Sentence Complement NO } \\
\text { complementiser } \\
\text { - subject and predicate complement } \\
\text { not preceded by a complementiser }\end{array}$ & I suspect [it was the middle of the week somewhere] \\
\hline $\begin{array}{l}\text { Sentence Complement WITH } \\
\text { complementiser } \\
\text { - subject and predicate complement } \\
\text { preceded by a complementiser }\end{array}$ & I did not remember [that it was wet going] \\
\hline $\begin{array}{l}\text { to Infinitive VP } \\
\text { - verb appearing in its infinitive form }\end{array}$ & and of course they had [to drive] \\
\hline $\begin{array}{l}\text { Transitive } \\
\text { - verb taking a direct object }\end{array}$ & I [saw her] \\
\hline Transitive + PP + Wh clause & and I [heard the news] [of [what happened in America]] \\
\hline Transitive + Prepositional Phrase & we [had our wedding [at Whitham]] \\
\hline Transitive + Sent Comp NO compl & you just [had this cold shiver] [just went through your body] \\
\hline Transitive + Sent Comp WITH compl & we [showed everyone else] [that we were special] \\
\hline Transitive + to Infinitive VP & I [want you] [to come and play] \\
\hline Transitive + Wh clause & I and [you had free drinks of Pepsi] [wherever you went] \\
\hline $\begin{array}{l}\text { Relative clause } \\
\text { - subject or object embedded clause }\end{array}$ & somebody [who I can trust] \\
\hline $\begin{array}{l}\text { Wh clause } \\
\text { - clause beginning with a 'Wh' word }\end{array}$ & [how much more do you want to know] \\
\hline \multicolumn{2}{|c|}{$\begin{array}{l}\text { *elements in square brackets [ ] represent the phrase(s) of interest and bold items specific lexical items } \\
\text { that signal certain phrases (e.g. prepositions or 'Wh' words). } \\
{ }^{\dagger} \text { Constructions are ordered alphabetically. Note that the same sentence could have more than one } \\
\text { possible classification. }\end{array}$} \\
\hline
\end{tabular}


Accepted / in press in Cortex.

\section{Results}

There were no significant differences between the groups in the number of words

$($ control mean $=756.8(4.4)$, patient mean $=765.4(14.2) ; \mathrm{U}=22.5, \mathrm{z}=-1.00, \mathrm{p}>0.3)$

or utterances $($ control mean $=94.6(7.4)$, patient mean $=103(25.1) ; \mathrm{U}=29.0, \mathrm{z}=-$

$0.316, \mathrm{p}>0.5)$ used in the analysis.

\subsection{Lexical counts and ratios}

Patients used more demonstrative pronouns (MWU $=7, \mathrm{n}=16, \mathrm{z}=-2.626, \mathrm{p}<0.01$ )

and more interrogative pronouns (MWU $=8, \mathrm{n}=16, \mathrm{z}=-2.521, \mathrm{p}<0.02)$ than

controls. There were no group differences in the use of indeterminate locative terms

or in the ratios of open to closed class words, light nouns to total nouns or light verbs to total verbs. See Table 2.

Table 2: Lexical counts and ratios

\begin{tabular}{|lcc|}
\hline & SD Patients & Controls \\
\hline Demonstrative pronouns* & $0.067(0.015)$ & $0.048(0.010)$ \\
\hline Interrogative pronouns* & $0.028(0.010)$ & $0.017(0.005)$ \\
\hline Indeterminate locative terms & $0.015(0.010)$ & $0.007(0.004)$ \\
\hline $\begin{array}{l}\text { Ratio of open : closed class } \\
\text { words }\end{array}$ & $0.596(0.088)$ & $0.643(0.093)$ \\
\hline $\begin{array}{l}\text { Ratio of light nouns : total } \\
\text { nouns }\end{array}$ & $0.130(0.142)$ & $0.082(0.039)$ \\
\hline $\begin{array}{l}\text { Ratio of light verbs : total } \\
\text { verbs }\end{array}$ & $0.433(0.076)$ & $0.420(0.099)$ \\
\hline
\end{tabular}

*significantly different $\mathrm{p}<0.05$

\subsection{Noun and Verb token frequency}

The Kolmogorov-Smirnov test was used to compare the overall distributions of items between patients and controls. For each individual, an individual distribution was generated that gave the proportion of total items (nouns or verbs) in each frequency bin. Rather than averaging across the group and losing power for a distributional 
Accepted / in press in Cortex.

analysis, proportion scores were then summed across a group to give an overall relative summed frequency value for that item (e.g. nouns in a given frequency bin) for the group. Frequency distributions based on these data were then compared using the KS test. Figure 1 presents group average data for ease of exposition.

Figure 1: Distributions of nouns and verbs across frequency bins.

Each graph shows data for SD Patients (black bars) and Controls (grey bars). The top row provides data for the nouns, and the bottom row data for verbs. The handscored data is shown on the left, and the automated extraction data on the right. Frequency bins increase in frequency (Log Celex Spoken wordform frequency per million) from left to right. Bars represent the group average, error bars are one standard error.
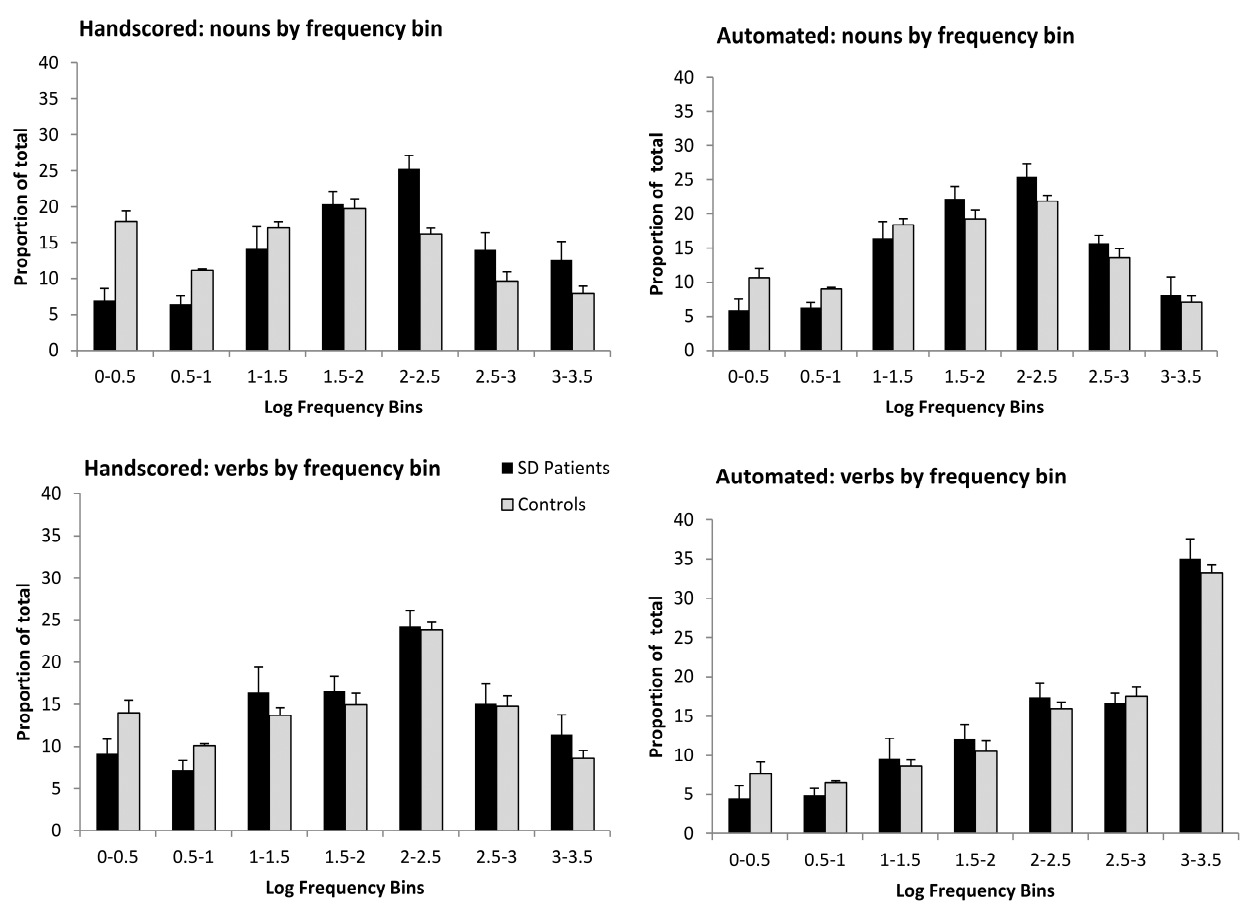
Accepted / in press in Cortex.

Patients and controls had significantly different frequency distributions for nouns in both the hand-scored $(\mathrm{N}=1,602, \mathrm{KS}$ test $=3.754, \mathrm{p}<0.001)$ and automated extraction data $(\mathrm{N}=1,602, \mathrm{KS}$ test $=1.924, \mathrm{p}<0.005)$ data. Figure 1 shows that patients had greater proportions of high frequency nouns, and lower proportions of low frequency nouns. This pattern was more defined in the hand-scored data.

There was a significant difference between patients and controls for the frequency distribution of verbs in the hand-scored $(\mathrm{N}=1,597, \mathrm{KS}$ test $=1.461, \mathrm{p}<0.05)$ but not the automated extraction data $(\mathrm{N}=1,598, \mathrm{KS}$ test $=1.007, \mathrm{p}>0.05)$ data. Figure 1 shows that patients tended to have a lower proportion of low frequency verbs. This pattern was also present in the automated extraction data for verbs, but this showed a substantially different pattern to the hand-scored data, as it had a strong left skew.

\subsection{Morphological and Syntactic Complexity: Auxiliary score}

The proportion of utterances falling into each auxiliary band was compared between subjects, giving 5 comparisons and a Bonferroni corrected significance level of $\mathrm{p}<0.01$. There was no difference in the proportion of utterances with an auxiliary score of 1 and 2 (the simplest forms). Patients had a greater proportion of utterances with an auxiliary score of 3 (Kruskal-Wallis $(\mathrm{K}-\mathrm{W})=9.763$, df $=1, \mathrm{p}<0.01)$ and lower proportions of utterances with scores of both $4(\mathrm{~K}-\mathrm{W}=4.339, \mathrm{df}=1, \mathrm{p}<0.05)$ and 5 or more, the most complex $(\mathrm{K}-\mathrm{W}=7.728, \mathrm{df}=1, \mathrm{p}<0.01)$. See Figure 2. 
Accepted / in press in Cortex.

Figure 2: Distribution of utterances across auxiliary score bands

Auxiliary score increases in complexity from left to right. Bars represent the group average data, error bars are one standard error.

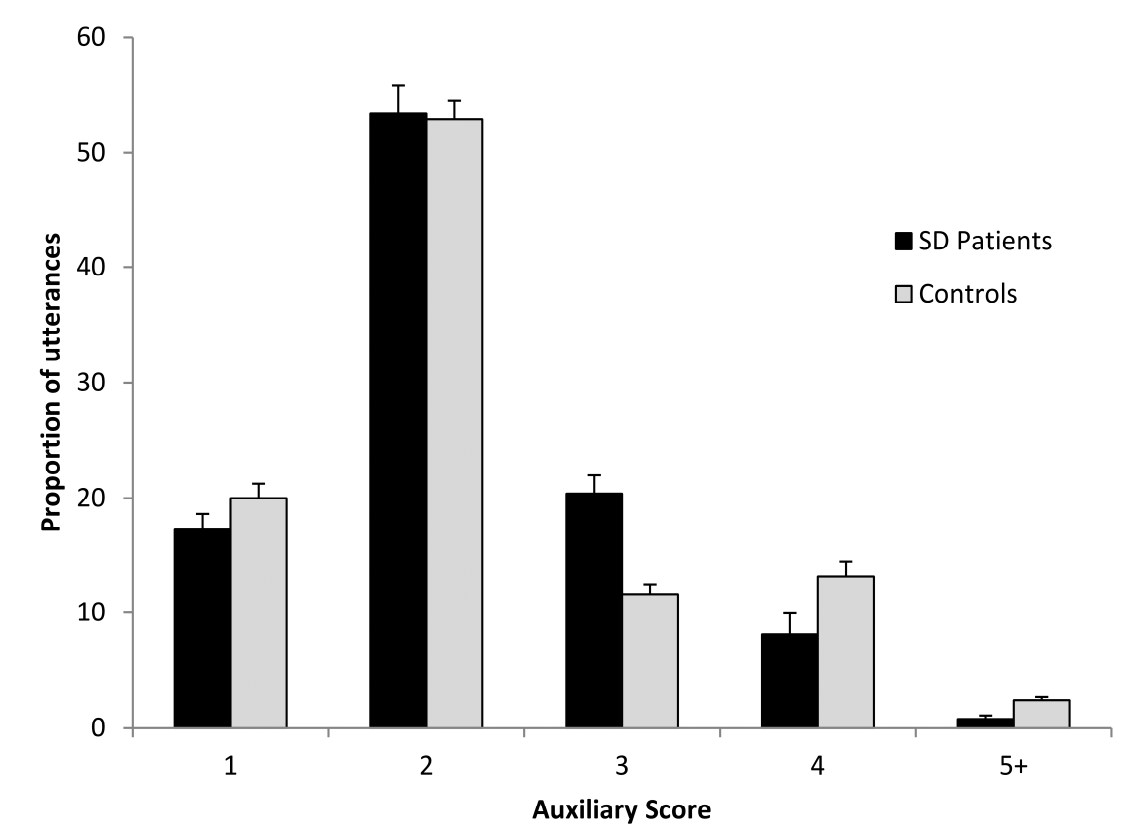

\subsection{Morphological and Syntactic Complexity: Distribution of syntactic constructions}

The same method as for the frequency distribution analysis was used to compare the distribution of syntactic constructions for hand-scored data (group summed proportions and the Kolmogorov-Smirnov test). The distributions of syntactic constructions were significantly different between patients and controls for the Roland classification scheme $(\mathrm{N}=1,594, \mathrm{KS}$ test $=1.839, \mathrm{p}<0.005)$ and nearly so with the Roland+ classification scheme $(\mathrm{N}=1,770, \mathrm{KS}$ test $=1.325, \mathrm{p}=0.06)$. 
Accepted / in press in Cortex.

Figure 3: Distribution of utterances across hand-scored syntactic constructions.

Constructions are ordered from top to bottom on the y-axis as the most to least

frequent, according to the Control data. Bars represent the group average, error bars are one standard error. Note that a given utterance (sentence) can have more than one classification. A full label for each construction can be found in Table $1.95 \%$ confidence intervals for each construction can be found in Table 3 .

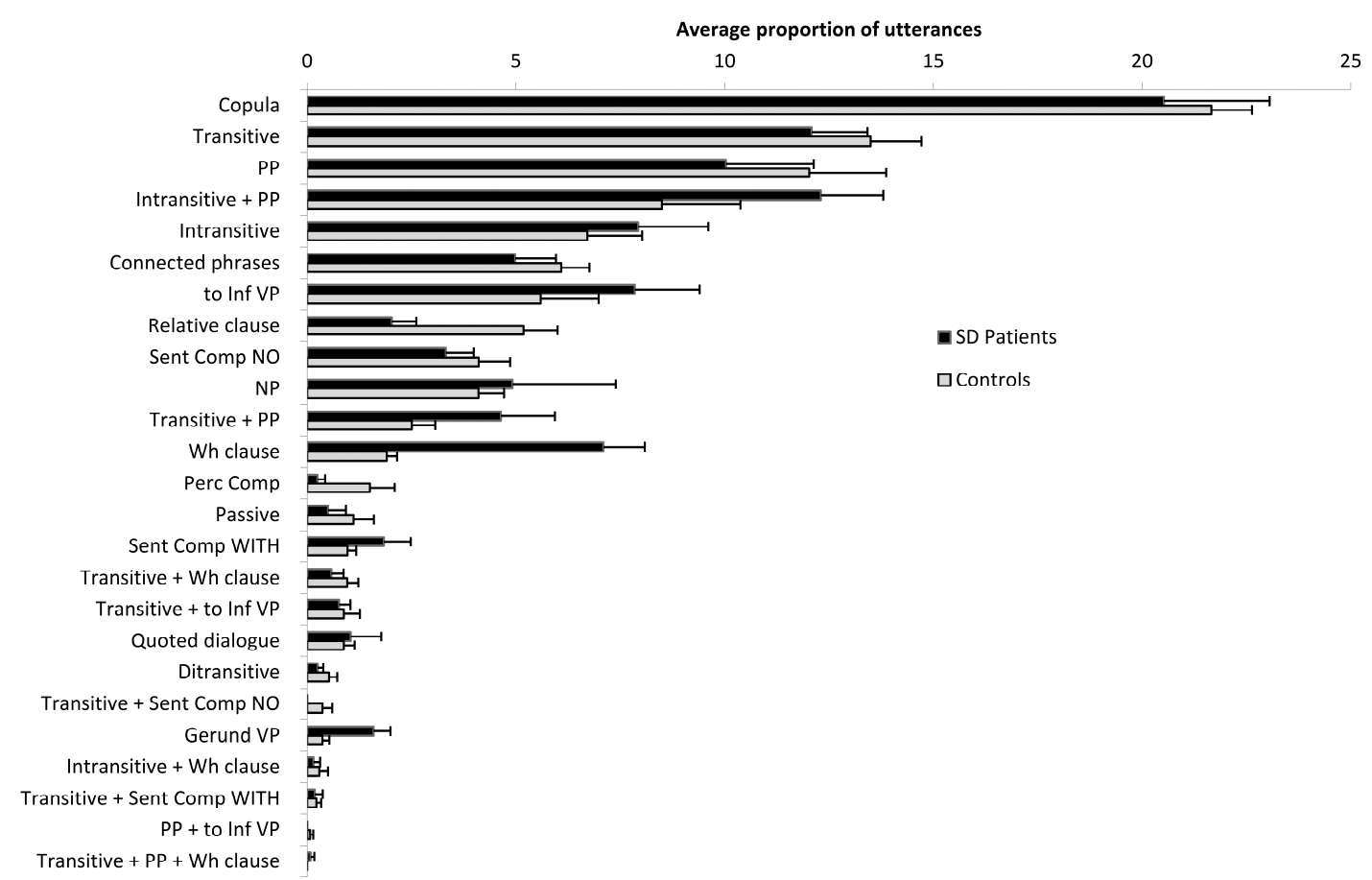

Figure 3 presents group average data for the Roland+ scheme, as it subsumes the original Roland classification. As there are numerous different syntactic constructions (25 in the Roland+ set), and they are not independent (each utterance can be classified more than once), it is not informative to complete multiple t-tests to compare individual constructions (hence the distribution analysis). However, to provide additional information on where interesting differences may lie, the confidence intervals (CI) for the difference between patients and controls for a given syntactic construction are provided in Table 3. This tells us the likely value of the difference and its direction, and will be used to give detail to the interpretation of the 
Accepted / in press in Cortex.

overall distribution differences. Confidence intervals were calculated using the mean and standard deviation values for each group, for each syntactic construction. If the confidence interval does not cross zero, this indicates that the difference between patients and controls for that construction is unlikely to be zero ( $95 \%$ confidence).

We have also chosen a more lenient criterion in which a trend is considered present if the confidence interval has a value of greater than 2 on one bound (positive or negative), and a value of less than 1 on the other bound.

Table 3: 95\% confidence intervals for the difference between SD Patients and Controls on the average proportion of utterances for a given syntactic construction

\begin{tabular}{|c|c|c|}
\hline \multirow[t]{2}{*}{ Syntactic construction $^{\mathrm{f}}$} & \multicolumn{2}{|c|}{$95 \% \mathrm{CI}$} \\
\hline & $\begin{array}{l}\text { Lower } \\
\text { bound }\end{array}$ & $\begin{array}{l}\text { Upper } \\
\text { bound }\end{array}$ \\
\hline Copula & -6.875 & 4.55 \\
\hline Transitive & -5.03 & 2.21 \\
\hline $\mathrm{PP}$ & -7.6 & 3.63 \\
\hline Intransitive + PP * & -0.983 & 8.6 \\
\hline Intransitive & -3.06 & 5.527 \\
\hline Connected phrases & -3.5 & 1.3 \\
\hline to Inf VP & -1.927 & 6.427 \\
\hline Relative clause $* *$ & -1.121 & -5.179 \\
\hline Sent Comp NO & -2.818 & 1.238 \\
\hline NP & -4.708 & 6.328 \\
\hline Transitive + PP * & -0.825 & 5.085 \\
\hline Wh clause $* *$ & 3 & 7.391 \\
\hline Perc Comp * & -2.59 & 0.07 \\
\hline Passive & -1.913 & 0.693 \\
\hline Sent Comp WITH * & -0.565 & 2.305 \\
\hline Transitive + Wh clause & -1.175 & 0.395 \\
\hline Transitive + to Inf VP & -1.06 & 0.84 \\
\hline Ditransitive & -0.741 & 0.201 \\
\hline Transitive + Sent Comp NO & $\mathrm{n} / \mathrm{a}$ & $\mathrm{n} / \mathrm{a}$ \\
\hline Gerund VP $* *$ & 0.327 & 2.133 \\
\hline Intransitive + Wh clause & -0.655 & 0.375 \\
\hline Transitive + Sent Comp WITH & -0.492 & 0.412 \\
\hline $\mathrm{PP}+$ to Inf VP & $\mathrm{n} / \mathrm{a}$ & $\mathrm{n} / \mathrm{a}$ \\
\hline Transitive $+\mathrm{PP}+\mathrm{Wh}$ clause & $\mathrm{n} / \mathrm{a}$ & $\mathrm{n} / \mathrm{a}$ \\
\hline
\end{tabular}

${ }^{1}$ Constructions are ordered from most to least frequent, according to Control data, as in Figure 3. $\mathrm{n} / \mathrm{a}$ - CI could not be calculated because one group had 0 instances of the construction ** Confidence intervals do not cross 0

* One CI bound is less than 1 with the other more than 2; taken here as a trend. 
Accepted / in press in Cortex.

Differences that indicate a trend are for the Intransitive + Prepositional Phrase (PP), Transitive + PP, and Sentence complement with complementiser (all SD > control) and perception complements (SD < Control). Differences for which the CI did not cross zero were the Relative clauses and the Gerund forms. Patients used fewer of the former and more of the latter.

For automated data (ShaC) we compared the proportions of utterances for each complexity level $(0,1,3,4,5,>5)$, giving 6 comparisons and a Bonferroni corrected significance level of $\mathrm{p}<0.08$. There was no difference in the proportion of utterances at any score level, see Figure 4.

$\underline{\text { Figure 4: Distribution of utterances across ShaC score bands }}$ Scores increase in complexity from left to right. Bars represent the group average data, error bars are one standard error.

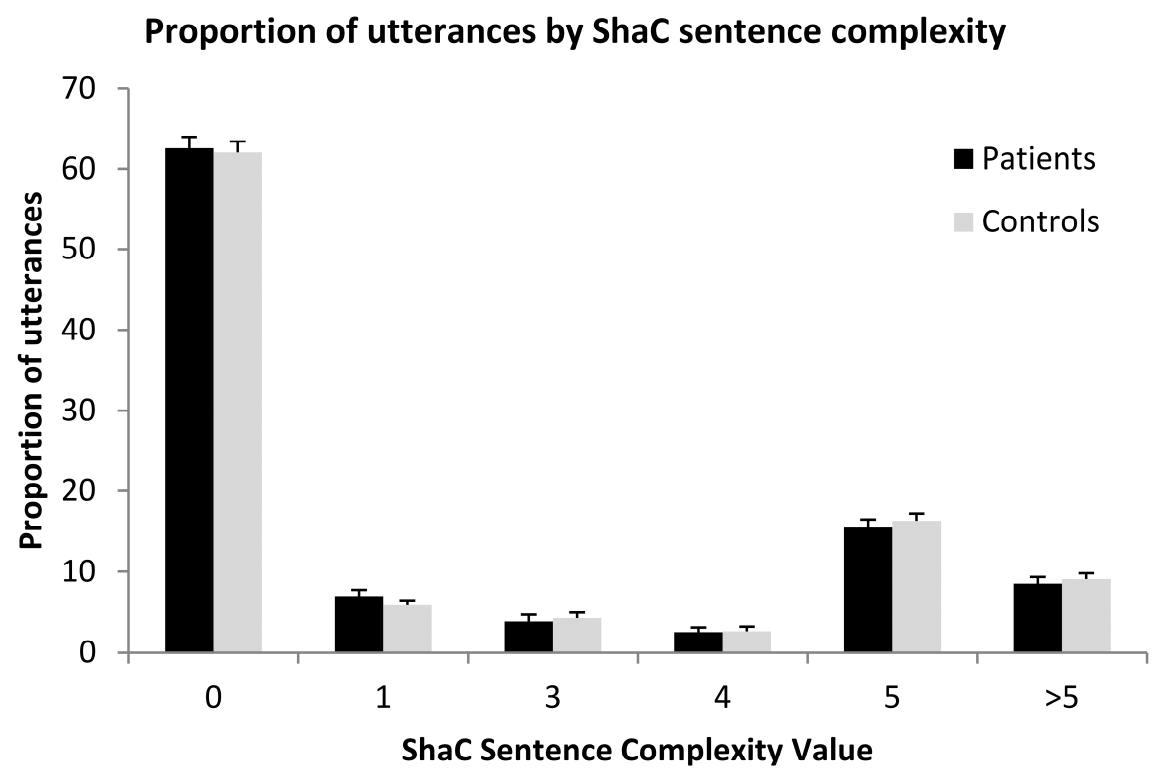


Accepted / in press in Cortex.

\section{Discussion}

We analysed data from the connected speech of 8 patients with Semantic Dementia and 8 healthy, age-matched controls. We first compared the frequency distributions of nouns and verbs, using both hand-scored data and data that were extracted using freely available text analysis software. The data for nouns were in line with previous findings (e.g. Bird et al., 2000): the distribution for SD patients was shifted towards high frequency items. This pattern was comparable across hand-scored and automated extraction, validating the use of the GATE software (Cunningham et al., $2002 ; 2011)$ to extract nouns from corpora. In contrast to nouns, we found a significant difference between SD patients and controls for the frequency distribution of verbs for the handscored data only, and markedly different distributions produced by hand-scored and automated extraction. The hand-scored data showed the predicted pattern, with fewer verbs in the bottom frequency bands for the patients. The automated data distribution was dominated by a strong left skew, with the vast majority of verbs falling into the highest frequency band. On inspecting the data, the key difference between hand-scored and automated extraction of verbs was that the GATE software was unable to differentiate between verbs used as auxiliaries (e.g. I had been walking) and those used as lexical verbs (e.g. I had a walk, I had been there). Therefore, both the patient and control data were dominated by auxiliary verbs, which are all very high frequency. It is feasible that GATE could be engineered to separate auxiliary and lexical verb use, as the software is open source and can be developed in this way (Cunningham et al., 2002).

We also compared the use of pronouns and certain lexical-ratios, but found no differences except for an increased use of demonstrative (e.g. this, that) and 
Accepted / in press in Cortex.

interrogative pronouns ('Wh' words) in SD patients. We expected to find an increased use of light terms, and for light nouns the SD patients had a numerically greater ratio ( 0.130 vs. 0.082$)$, but it did not reach significance. The ratio of light verbs to all verbs was comparable across SD patients and controls (0.433 vs. 0.420$)$ with light verbs making up nearly half of all verbs. Since light verbs are employed frequently by all native speakers of English, their use is likely to be near ceiling even in the controls. This phenomenon may also be especially characteristic of speech samples collected from this kind of semi-structured interview, where the tester's questions about life events provoke responses like "I went to school in Birmingham", "We had our first child in 1970" etc. By comparison, description of a constrained scene like a video or complex picture invites the use of specific, heavier verbs (such as 'falling' or 'overflowing' in the Cookie Theft picture) and, in these cases it has been found that SD patients do rely on more high frequency, generic verbs than healthy speakers (Meligne et al., 2011). This is not meant to imply that picture description is a better method of eliciting connected speech than interview; if anything, some recent comparisons of the two methods have concluded that interview is more sensitive for detecting abnormalities in the syntax/structure of speech (Sajjadi et al., 2012; Sajjadi, Patterson, Tomek, \& Nestor, 2013). It is not, however, surprising if there are some advantages of each method for assessing specific aspects of production. In the interview technique used here, the replies to questions are almost completely unconstrained; this means that the patients would have been able to rely on 'known' vocabulary and would therefore be less likely to produce frank errors. This makes the data closer to real life conversation and the natural speech that these patients produce, and goes some way to explaining why SD patients typically sound 
Accepted / in press in Cortex.

so normal in conversation. In more constrained tasks, the differences between patients and controls would be more salient.

SD patients used fewer highly complex auxiliary constructions and more constructions of middling complexity. For the syntactic analysis, SD patients differed from controls on a number of different construction types for the hand-scored analysis. Linking back to morphological production, SD patients produced more constructions with a gerund (a verb with an 'ing' suffix) which is the second most frequent in English (see Table 1 in Faroqi-Shah \& Thompson, 2004). Alongside data from speech errors indicating that SD patients make substitution errors on both free and bound morphological forms (Meteyard \& Patterson, 2009), these data further support the hypothesis that SD patients have difficulty producing complex morphology, and use highly frequent forms more often. Our results demonstrate that this has a further impact on morpho-syntax, limiting the production of complex auxiliary constructions. This is also in line with the case-study from Benedet et al (2006) who found that Spanish patient ILJ had difficulty with complex inflectional and derivational morphology, with a substantially reduced success in producing passive forms which require an auxiliary. These data do not conflict with previous findings of comparable morphology between SD patients and controls (e.g. Kave et al., 2007) since (a) SD patients do not tend to omit inflections and will therefore not be judged abnormal on measures designed to detect agrammatic speech, and (b) comparisons based on average values can mask subtle differences in the distribution of forms. 
Accepted / in press in Cortex.

The hand-scored syntactic analysis also showed a clear impact of lexical retrieval on grammatical encoding. SD patients produced a greater proportion of intransitive and transitive constructions with prepositional phrases, more constructions with 'Wh' words and more sentence complements with a complementiser. In all cases, these are constructions that require the use of a highly frequent closed class lexical item (a preposition, an interrogative pronoun or a complementiser, usually 'that'). The patients used more demonstrative and interrogative pronouns and, in a mirror image of this, constructions that require their inclusion were also more characteristic of their speech. The production of other constructions that also include highly-frequent closed class items (e.g. prepositional phrases, connected phrases) may already be at ceiling in both patients and controls due to their high frequency. In contrast, those beginning with 'Wh' words and complementisers are less frequent in production so there is more room for variation. More constrained tasks that force the production of particular constructions may be able to demonstrate this effect more clearly.

Finally, SD patients also produced fewer relative clauses. These are embedded clauses that elaborate the subject or object of a sentence (e.g. The man [who wore a hat] saw the book [that was lying on a chair]). Relative clauses are embedded within an existing sentence, and require additional information to be retrieved and lexicalised. By contrast, we did not find that SD patients used fewer passive constructions, which have a non-canonical word order. Embedding and non-canonical word order are arguably different forms of complexity. Passive constructions in English include an auxiliary 'was' or 'were' and a preposition 'by' or 'with' (e.g. The dog bit the boy, the boy was bitten by the dog; music entertained the guests, the guests were entertained with music), neither of which we predict to be problematic in SD. Passives are also 
Accepted / in press in Cortex.

reliant on the correct assignment of thematic roles (who is doing what to whom), about which we make no predictions. It may be that difficulties with passives would be found in a more controlled experiment demanding their use (as reported by Benedet et al., 2006, for Spanish), or that it is not a sufficiently complex, atypical construction in English to cause measurable difficulties. In contrast, embedded constructions such as relative clauses require the maintenance of a hierarchy of information and additional detail about the subject or object to which the embedded clause refers. Both of these things may call upon additional semantic support during their production.

The ShaC extracted data uncovered no differences between patients and controls in the distribution of utterances at each level of developmental acquisition. The ShaC analysis places different constructions together depending on their age of acquisition, and so does not differentiate between constructions acquired at the same age, that may have different closed class constituents. We also accept that it is a rough and ready proxy for syntactic typicality. However, it does not allow the finer-grained analysis completed for the hand-scored data, in which we analysed each construction separately. Thus, an analysis that collapsed across different constructions does not show differences between control and patient data, whereas a syntactic analysis that is sensitive to lexical retrieval does. This may explain why previous work has not found differences between patient and control groups, as the effect is not simply one of 'complexity' or frequency of whole syntactic forms. The impact of lexical retrieval on production that we see in SD patients further supports incremental theories of speech production. 
Accepted / in press in Cortex.

\section{Conclusion}

Detailed hand-scored analyses revealed differences between SD patients and controls in the lexical, morphological and syntactic forms of connected speech. Automated analyses using existing, freely available software demonstrated similar differences only in lexical measures. For these tools to be increasingly useful for corpora analysis they will need to be tailored more specifically to the language impairment in question (see other papers in this volume).

SD patients produce more high frequency nouns and fewer low frequency nouns and verbs. They produce fewer complex auxiliary forms as part of verb phrases, and tend to use high frequency inflections (e.g. 'ing') more often. Their profound anomia and reliance on high frequency lexical items has implications for the kinds of syntactic constructions that they use. This is likely to be a product of the dynamic nature of production: a sentence is started and requires completion, certain items are more easily available and the reduced semantic support means that structures which demand the selection of multiple inflections, or additional semantic information (e.g. relative clauses) are more difficult to execute. This leads to a reliance on the simpler syntactic constructions (e.g. a simple transitive or intransitive plus a prepositional phrase or a 'Wh' clause).

Under theories that propose the selection of morphological and syntactic forms to be independent of lexical retrieval, and reliant instead on the application of rules to produce certain structures, there is no clear reason to predict differences between SD patients and controls without an ad hoc and unjustified assumption of an additional 'rule' deficit. We argue that the data support a model of speech production in which 
Accepted / in press in Cortex.

sentences are produced incrementally, there is no hard boundary between lexical retrieval and grammatical encoding, and production emerges from the on-line interaction between multiple available sources of information (F. Ferreira and Swets, 2002; Seidenberg and MacDonald, 2001; Timmermans et al., 2012). The mechanisms by which morphological and syntactic forms are sequentially ordered and phonologically realised remain essentially intact in SD, but forms which demand a greater input from lexical/semantic information (e.g. to select multiple inflections or closed-class items) will receive insufficient support. Rather than committing frank errors, such as omissions or mis-ordering, SD patients simply produce fewer of these forms. The range and complexity of their speech therefore shows ever decreasing circles, with the reduced flexibility of lexical retrieval producing a parallel reduction in the range of morphological and syntactic levels of production.

Acknowledgements: We are grateful to Professor John R Hodges for permission to analyse and publish results from the interviews that he conducted with these SD patients who were also under his clinical care.

\section{References}

Ash, S., Moore, P., Antani, S., McCawley, G., Work, M., \& Grossman, M. (2006).

Trying to tell a tale: discouse impairments in progressive aphasia and frontotemporal dementia. Neurology, 66, 1405-1413.

Benedet, M., Patterson, K., Gomez-Pastor, I., \& Garcia de la Rocha, M. L. (2006). "Non-semantic" aspects of language in semantic dementia: As normal as they're said to be? Neurocase, 12(15-26). 
Accepted / in press in Cortex.

Bird, H., Lambon Ralph, M. A., Patterson, K., \& Hodges, J. R. (2000). The rise and fall of frequency and imageability: Noun and verb production in semantic dementia. Brain and Language, 73(17-49).

Bock, K. (1987). An effect of accessibility of word forms on sentence production. Journal of Experimental Psychology: Learning, Memory and Cognition., 12, $575-586$.

Bock, K. (1999). Language Production. In R. Wilson \& F. Keil (Eds.), MIT encyclopedia of the cognitive sciences (pp. 453-456). Cambridge, MA.: MIT Press.

Bock, K., \& Levelt, W. (1994). Language Production: Grammatical Encoding. In M. A. Gernsbacher (Ed.), Handbook of Psycholinguistics (pp. 945-984). San Diego: Academic Press.

Bock, K., \& Warren, R. K. (1985). Conceptual accessibility and syntactic structure in sentence formulation. Cognition, 21, 47-67.

Bozeat, S., Lambon Ralph, M. A., Garrard, P., Patterson, K., \& Hodges, J. R. (2000). Non-verbal semantic impairment in semantic dementia. Neuropsychologia, 38, $1207-1215$.

Breedin, S. D., \& Saffran, E. M. (1999). Sentence processing in the face of semantic loss: A case study. Journal of Experimental Psychology: General., 128, 547562.

Chang, F., Dell, G. S., \& Bock, K. (2006). Becoming Syntactic. Psychological Review, 113(2), 234-272.

Cunningham, H., Maynard, D., Bontcheva, K., \& Tablan, V. (2002). GATE: A Framework and Graphical Development Environment for Robust NLP Tools and Applications. Paper presented at the Proceedings of the 40th Anniversary 
Accepted / in press in Cortex.

Meeting of the Association for Computational Linguistics (ACL'02), Philadelphia.

Cunningham, H., Maynard, D., Bontcheva, K., Tablan, V., Aswani, N., Roberts, I., et al. (2011). Text Processing with GATE (Version 6): University of Sheffield Department of Computer Science.

Dell, G. S., Chang, F., \& Griffin, Z. (1999). Connectionist Models of Language Production: Lexical Access and Grammatical Encoding. Cognitive Science, 23(4), 517-542.

Faroqi-Shah, Y., \& Thompson, C. K. (2004). Semantic, lexical and phonological influences on the production of verbs inflections in agrammatic aphasia. Brain and Language, 89, 484-498.

Ferreira, F., \& Swets, B. (2002). How Incremental is Language Production? Evidence from the Production of Utterances Requiring the Computation of Arithmetic Sums. Journal of Memory and Language, 46, 57-84.

Ferreira, V. S., \& Dell, G. S. (2000). Effect of Ambiguity and Lexical Availability on Syntactic and Lexical Production. Cognitive Psychology, 40, 296-340.

Garrett, M. F. (1980). Levels of Processing in Sentence Production. In B. Butterworth (Ed.), Language Production. Volume 1: Speech and Talk. London: Academic Press.

Goldrick, M. (2006). Limited interaction in Speech Production. Language and Cognitive Processes, 21(7-8), 817-855.

Hodges, J. R., \& Patterson, K. (2007). Semantic dementia: a unique clinicopathological syndrome. Lancet Neurology, 6, 1004-1014 
Accepted / in press in Cortex.

Hodges, J. R., Patterson, K., Oxbury, S., \& Funnell, E. (1992). Semantic dementia: Progressive Fluent aphasia with temporal lobe atrophy. Brain, 115, 17831806.

Irish, M., Hornberger, M., Lah, S., Miller, L., Pengas, G., Nestor, P., et al. (2011). Profiles of recent autobiographical memory retrieval in semantic dementia, behavioural-variant frontotemporal dementia, and Alzheimer's disease. Neuropsychologia, 49, 2694-2702.

Kave, G., Leonard, C., Cupit, J., \& Rochon, E. (2007). Structurally well-formed narrative production in the face of severe conceptual deterioration: A longitudinal case study of a woman with semantic dementia. Journal of Neurolinguistics, 20, 161-177.

Kopelman, M. D., Wilson, B. A., \& Baddeley, A. D. (1990). The autobiographical memory interview. Bury St Edmunds: Thames Valley Test Company.

Levelt, W. J. M., Roelofs, A., \& Meyer, A. S. (1999). A theory of lexical access in speech production. Behavioral and Brain Sciences, 22, 1-75.

Levin, B. (1993). English Verb Classes and Alternations. London: University of Chicago Press.

McDonald, J. L., Bock, K., \& Kelly, M. H. (1993). World and word order: Semantic, phonological, and metrical determinants of serial position. Cognitive Psychology, 25(188-230).

McKinnon, M. C., Miller, B., Black, S., Moscovitch, M., \& Levine, B. (2006). Autobiographical memory in semantic dementia: Implications for theories of limbic-neocortical interactions in remote memory. Neuropsychologia, 44(12), 2421-2429. 
Accepted / in press in Cortex.

Meligne, D., Fossard, M., Belliard, S., Moreaud, O., Duvignau, K., \& Demonet, J.-F. (2011). Verb production during action naming in semantic dementia. Journal of Communication Disorders, 44, 379-391.

Meteyard, L., \& Patterson, K. (2009). The relation between content and structure in language production: An analysis of speech errors in semantic dementia. Brain and Language, 110(3), 121-134.

Nestor, P., Graham, K. S., Bozeat, S., Simons, J. S., \& Hodges, J. R. (2002). Memory consolidation and the hippocampus: Further evidence from studies of autobiographical memory in semantic dementia and frontal variant frontoemporal dementia. Neuropsychologia, 40(6), 633-654.

Nickels, L., \& Howard, D. (2000). When the words won't come: Relating impairments and models of spoken word production. In L. R. Wheeldon (Ed.), Aspects of Language Production. Hove, UK.: Psychology Press.

Patterson, K. (in press). Language disorders in neurodegenerative disease: insights into the organisation of semantic memory and language in the human brain. In L.-G. O. Nilsson, N. (Ed.), Tsukuba International Conference on Memory (Vol. 9).

Patterson, K., Lambon Ralph, M. A., Hodges, J. R., \& McClelland, J. L. (2001). Deficits in irregular past-tense verb morphology associated with degraded semantic knowledge. Neuropsychologia, 39(7), 709-724.

Patterson, K., Lambon Ralph, M. A., Jefferies, E., Woollams, A. M., Jones, R., Hodges, J. R., et al. (2006). "Presemantic" Cognition in Semantic Dementia: Six Deficits in Search of an Explanation. Journal of Cognitive Neuroscience, $18,169-183$. 
Accepted / in press in Cortex.

Patterson, K., \& MacDonald, M. C. (2006). Sweet nothings: Narrative speech in semantic dementia. In S.Andrews (Ed.), From Inkmarks to Ideas: Current issues in lexical processing (pp. 299-317). Hove, UK.: Psychology Press.

Roland, D., Dick, F., \& Elman, J. L. (2007). Frequency of basic English grammatical structures: A corpus analysis. Journal of Memory and Language, 57, 348-379.

Saffran, E. M., Berndt, R. S., \& Schwartz, M. F. (1989). The Quantitative Analysis of Agrammatic Production: Procedure and Data. Brain and Language, 37, 440479.

Sajjadi, S. A., Patterson, K., Tomek, M., \& Nestor, P. (2012). Abnormalities of connected speech in semantic dementia vs. Alzheimer's disease. Aphasiology. doi:10.1080/02687038.2012.654933

Sajjadi, S. A., Patterson, K., Tomek, M., \& Nestor, P. (2013). Abnormalities of connected speech in the non-semantic variant presentations of primary progressive aphasia. Aphasiology, 26, 1219-1237

Schiller, N. O., \& Caramazza, A. (2006). Grammatical gender seletion and the representation of morphemes: The production of Dutch diminutives. Language and Cognitive Processes, 21(7-8), 945-978.

Schiller, N. O., \& Costa, A. (2006). Different Selection Principles of Freestanding and Bound Morphemes in Language Production. Journal of Experimental Psychology: Learning, Memory and Cognition., 32(5), 1201-1207.

Schriefers, H., Jescheniak, J. D., \& Hantsch, A. (2005). Selection of gender-marked morphemes in speech production. Journal of Experimental Psychology: Learning, Memory and Cognition., 31, 159-168. 
Accepted / in press in Cortex.

Seidenberg, M. S., \& MacDonald, M. C. (1999). A Probabilistic Constraints Approach to Language Acquisition and Processing. Cognitive Science, 23(4), $569-588$.

Seidenberg, M. S., \& MacDonald, M. C. (2001). Constraint Satisfaction in Language Acquisition and Processing. In M. H. Christiansen \& N. Chater (Eds.), Connectionist Psycholinguistics (pp. 281-318). Westport: Greenwood: Ablex Publishing.

Timmermans, M., Schriefers, H., Sprenger, S., \& Dijkstra, T. (2012). Describing simple events: The dynamics of incremental grammatical encoding. Journal of Cognitive Psychology, 24(4), 441-456.

Vigliocco, G., \& Hartsuiker, R. J. (2002). The interplay of meaning, sound, and syntax in sentence production. Psychological Bulletin, 128, 442-472.

Vigliocco, G., Warren, J. D., Arcuili, J., Siri, S., Scott, S., \& Wise, R. (2006). The role of semantics and grammatical class in the neural representation of words. Cerebral Cortex, 16(12), 1790-1796.

Voss, M. (2005). ShaC (Shallow Syntactic Complexity Analyzer). November 2012, from http://www.ai.uga.edu/caspr/

Warrington, E. K. (1975). The selective impairment of semantic memory. Quarterly Journal of Experimental Psychology, 27, 635-657.

Wilson, S. M., Henry, M. L., Besbris, M., Ogar, J. M., Dronkers, N. F., Jarrold, W., et al. (2010). Connected speech production in three variants of primary progressive aphasia. Brain, 133, 2069-2088.

Woollams, A. M., Lambon Ralph, M. A., Plaut, D. C., \& Patterson, K. (2007). SDsquared: on the association between semantic dementia and surface dyslexia. Psychological Review, 111(2), 316-339. 